\title{
Exosomes from tamoxifen-resistant breast cancer cells transmit drug resistance partly by delivering miR-9-5p
}

Jianhui Liu', Shaoliang Zhu², Wei Tang ${ }^{1}$, Qinghua Huang ${ }^{1}$, Yan Mei ${ }^{1}$ and Huawei Yang ${ }^{1 *}$ (1)

\begin{abstract}
Background: Resistance to drug therapy is a major impediment for successful treatment of patients suffering from breast cancer (BC). Tamoxifen (TAM) is an extensively used therapeutic agent, which substantially reduces the risk of recurrence and associated mortality in BC. This study demonstrated that exosomal transfer of microRNA-9-5p (miR9-5p) enhanced the resistance of MCF-7 cells to TAM.

Methods: Initially, BC-related differentially expressed genes (DEGs) and their upstream regulatory miRNAs were identified. The TAM-resistant MCF-7 (MCF-7/TAM) cell line and the non-medicated sensitive MCF-7 cell line were formulated, followed by isolation of the exosomes. Next, the apoptosis rate of exosome-treated MCF-7 cells was determined after co-culture with TAM. The interaction between miR-9-5p and ADIPOQ was identified by a combination of bioinformatic analysis and luciferase activity assay. In order to validate the effect of miR-9-5p and ADIPOQ on TAM resistance in the MCF-7 cells in vitro and in vivo, miR-9-5p was delivered into the exosomes. ADIPOQ and miR-9-5p were identified as the BC-related DEG and upstream regulatory miRNA.
\end{abstract}

Results: Exosomes derived from the MCF-7/TAM cells could increase the resistance of MCF-7 cells to TAM. Notably, miR-9-5p altered the sensitivity of BC cells to TAM. In addition, ADIPOQ was negatively regulated by miR-9-5p. Furthermore, MCF-7/TAM cell-derived miR-9-5p inhibited the apoptosis of MCF-7 cells, and promoted the cell resistance to TAM. In vivo experiments in nude mice ascertained that the tumor injected with exosomal miR-9-5p showed improved resistance to TAM.

Conclusions: Exosomal transfer of miR-9-5p augmented the drug resistance of BC cells to TAM by down-regulating ADIPOQ, suggesting its functionality as a candidate molecular target for the management of BC.

Keywords: Breast cancer, Drug resistance, Exosomes, MicroRNA-9-5p, ADIPOQ, Tamoxifen, MCF-7, MCF-7/TAM

\section{Background}

Breast cancer $(\mathrm{BC})$ is the most frequently occurring malignancy in females with a rising incidence worldwide $[1,2]$. In China, BC is regarded the 6th leading cause of cancer-associated mortality [3]. The currently adopted

\footnotetext{
*Correspondence: lordyhw@163.com

${ }^{1}$ The First Department of Breast Surgery, Guangxi Medical University

Cancer Hospital, Nanning 530021, People's Republic of China

Full list of author information is available at the end of the article
}

treatment modalities for $\mathrm{BC}$ include surgical resection, chemotherapy, endocrine therapy, radiation therapy, and integrative multi-modal therapies [4, 5]. Tamoxifen (TAM) has been extensively used as a therapeutic agent for $\mathrm{BC}$ with a decreasing invasive potential capacity, although it has also been associated with adverse outcomes $[6,7]$. However, TAM resistance is a frequent manifestation during $\mathrm{BC}$ management, which may be attributed to the high tumor levels of estrogen receptor [8]. the original author(s) and the source, provide a link to the Creative Commons licence, and indicate if changes were made. The images or other third party material in this article are included in the article's Creative Commons licence, unless indicated otherwise in a credit line to the material. If material is not included in the article's Creative Commons licence and your intended use is not permitted by statutory regulation or exceeds the permitted use, you will need to obtain permission directly from the copyright holder. To view a copy of this licence, visit http://creativecommons.org/licenses/by/4.0/. The Creative Commons Public Domain Dedication waiver (http://creativeco mmons.org/publicdomain/zero/1.0/) applies to the data made available in this article, unless otherwise stated in a credit line to the data. 
Extracellular vesicles, including exosomes, have been examined in regard to anti-cancer investigations as modes of provision for anti-cancer drugs, as they may reduce resistance and entail fewer adverse effects than the free drugs [9]. Exosomes have been defined as homogeneously shaped vesicles, with a size of $40-00 \mathrm{~nm}$ in diameter [10]. While exosome-delivered molecules may hasten oncogenesis, aggressiveness, and drug resistance in $\mathrm{BC}$, some exosomes can also transport anti-cancer drugs into $\mathrm{BC}$ cells, thereby minutely reducing resistance [11]. In the cancer microenvironment, the cancer cellsecreted exosomes and microRNAs (miRNAs) can be internalized by other cells, shuttled in the exosomes, and delivered to the recipient cells to mediate gene expression [12]. Accumulating evidence has ascertained the functionality of miRNAs as critical regulators of chief genes associated with drug resistance, and traditional therapies, moreover, in combination with miRNA-based treatment, it may be a promising option for the management of drug resistant BC [13].

In this study, we utilized microarray-based bioinformatic analysis to identify the differentially expressed gene ADIPOQ and its regulatory miRNA microRNA9-5p (miR-9-5p) for subsequent experimentation. Previous bioinformatics prediction and functional assays have identified an association between the functional miRNAmRNA networks with the invasiveness of BC cells [14]. An existing study elicited the clinicopathological role of miR-9 in BC metastasis, where it was highly expressed in the primary breast tumors from patients with advanced BC [15]. Additionally, miR-9-5p has been identified to facilitate the proliferation, migration, and invasion of non-small cell lung cancer cells by targeting and negatively regulating the TGFBR2 expression [16]. ADIPOQ, a gene encoding for adiponectin, is present on chromosome $3 \mathrm{q} 27$, and principally comprises of three exons and two introns [17]. Elevated ADIPOQ expression is associated with a superior survival rate of $B C$ patients receiving chemotherapy and autophagic BC cell death [18]. In this study, we hypothesized that exosome-mediated delivery of miR-9-5p in the TAM resistant BC cells may mediate drug resistance and act via involvement of ADIPOQ.

\section{Materials and methods}

\section{Ethics statement}

All animal experiments were conducted in compliance with the guidelines of the Guangxi Medical University.

\section{Construction and culture of TAM-resistant MCF-7 (MCF-7/ TAM) cell line}

Initially, the MCF-7 cells (Cell Bank of the Chinese Academy of Sciences, Shanghai, China) were cultured in high-glucose Dulbecco's modified Eagle's medium
(DMEM, Gibco, Grand Island, NY, USA) containing $10 \%$ fetal bovine serum (FBS, Gibco, Grand Island, NY, USA). MCF-7/TAM cells (Toronto Research Chemicals, North York, Ontario, Canada) were incubated in complete high-glucose DMEM containing $1.0 \times 10^{-7} \mathrm{~mol} / \mathrm{L}$ TAM for a period of 6 months. After establishment of drug resistance, the cells were cultured in high-glucose DMEM medium containing 10\% FBS. The MCF-7/TAM cells were treated with $10 \mathrm{mg} / \mathrm{mL}$ or $20 \mathrm{mg} / \mathrm{mL}$ Gefitinib (AstraZeneca LP, Wilmington, DE, USA) for $48 \mathrm{~h}$, followed by a regimen of incubation with $5 \% \mathrm{CO}_{2}$ at $37^{\circ} \mathrm{C}$.

\section{Isolation and characterization of exosomes}

Exosome free FBS was prepared by ultracentrifugation at $1 \times 10^{6} \mathrm{~g}$ for $16 \mathrm{~h}$ (XL-100 K, Beckman Coulter, Fullerton, CA, USA) at $4{ }^{\circ} \mathrm{C}$. After $48-72 \mathrm{~h}$ of incubation, the culture medium was harvested, and the exosomes were isolated by ultracentrifugation. Briefly, the cell culture medium was sequentially centrifuged at $300 \mathrm{~g}$ for $10 \mathrm{~min}$, at $2000 \mathrm{~g}$ for $15 \mathrm{~min}$ and at $12,000 \mathrm{~g}$ for $30 \mathrm{~min}$ to remove the floating cells and cell debris. Next, the medium was filtered using a $0.22 \mu \mathrm{m}$ filter. The supernatant was then ultracentrifuged at $1 \times 10^{6} \mathrm{~g}$ for $2 \mathrm{~h}$ at $4{ }^{\circ} \mathrm{C}$, and subjected to a second regimen of ultracentrifugation under similar conditions. Finally, the pellets were re-suspended using $100 \mathrm{~mL}$ of the phosphate buffered saline (PBS) and analyzed by NanoSight NS300 for concentration and size of exosomes.

\section{Cellular uptake of exosomes}

A total of $200 \mathrm{pg}$ exosomes were added to $1 \mathrm{~mL}$ of the Diluent $\mathrm{C}$ solution. Then, $4 \mu \mathrm{L}$ of PKH67 fluorescent staining solution was added into another Eppendorf (EP) tube containing $1 \mathrm{~mL}$ of the Diluent $\mathrm{C}$ solution. These two solutions were mixed for $5 \mathrm{~min}$, followed by the addition of $10 \mathrm{~mL}$ of $1 \%$ bovine serum albumin (BSA) to facilitate the binding of excessive staining solution. The mixed solution was centrifuged at $100,000 \mathrm{~g}$ at $4{ }^{\circ} \mathrm{C}$ for $2 \mathrm{~h}$, with removal of the supernatant. Finally, the solution was centrifuged at $100,000 \mathrm{~g}$ at $4{ }^{\circ} \mathrm{C}$ for $2 \mathrm{~h}$ to isolate the exosome pellet, which was resuspended using complete medium. MCF-7 cells were incubated with PKH67-labeled exosomes and observed under a confocal microscope.

\section{Transmission electron microscopy (TEM)}

The exosomes obtained by centrifugation of $400 \mathrm{~mL}$ of the medium at high-speed were fixed in $2 \%$ glutaraldehyde overnight at $4{ }^{\circ} \mathrm{C}$. Then, exosomes were fixed with $1 \% \mathrm{OsO}_{4}$ for $1 \mathrm{~h}$, dehydrated in ethanol, and finally embedded in resin. The embedded sample was sliced using a microtome and saturated sodium periodate and $0.1 \mathrm{~N}$ hydrochloric acid were each added onto the 
sections. After $10 \mathrm{~min}$, the sections were observed under a TEM (H-500, HITACHI, Tokyo, Japan).

\section{Cell transfection}

Cells in the logarithmic growth phase were seeded in 6 -well plates at a density of $6.0 \times 10^{5}$ cells per well. According to the provided instructions of the Lipofectamine 2000 Transfection Kit, the MCF-7 cells and MCF-7/TAM cells were transfected with mimic and inhibitor, respectively. A 25 pmol mimic or inhibitor and $10 \mu \mathrm{L}$ transfection reagent was added to each well to attain a final concentration of $10 \mathrm{pmol} / \mathrm{mL}$, followed by incubation at $37{ }^{\circ} \mathrm{C}$ with $5 \% \mathrm{CO}_{2}$. The cells were grouped as follows: the miR-9-5p mimic group (transfected with synthetic miR-9-5p mimic), miR-9-5p mimic-NC group (transfected with miR-9-5p mimic negative control sequence), miR-9-5p inhibitor group (transfected with miR-9-5p inhibitor), and miR-9-5p inhibitor-NC group (transfected with miR-9-5p inhibitor and negative control sequence). Each experiment was conducted 3 times independently. The cells were cultured for $48 \mathrm{~h}$, and the exosomes were harvested for subsequent experimentation.

\section{Co-culture of exosomes with MCF-7 cells}

Exosomes harvested from the transfected MCF-7 cells and MCF-7/TAM cells were co-cultured with MCF-7 cells for $48 \mathrm{~h}$ for subsequent experimentation. The MCF-7 cells were incubated with; exosomes extracted from the MCF-7 cells (MCF-7-exo group), exosomes extracted from the MCF-7 cells transfected with miR9-5p mimic-NC ([MCF-7+ NC-mimic]-exo group), exosomes extracted from the MCF-7 cells transfected with miR-9-5p mimic ([MCF-7+ miR-9-5p mimic]exo group), exosomes extracted from MCF-7/TAM cells (MCF-7/TAM-exo), exosomes extracted from the MCF-7/TAM cells transfected with miR-9-5p inhibitorNC ([MCF-7/TAM+NC-inhibitor]-exo group), and exosomes extracted from the MCF-7/TAM cells transfected with miR-9-5p inhibitor ([MCF-7/TAM + miR$9-5 p$ inhibitor]-exo group) respectively.

\section{Western blot analysis}

The lysed samples were centrifuged at $7000 \mathrm{~g}$ for $30 \mathrm{~min}$ at $4{ }^{\circ} \mathrm{C}$ to eliminate any cell debris. The supernatant was collected, and the total protein concentration was measured with a bicinchoninic acid kit. A total of $50 \mu \mathrm{g}$ of the protein content was dissolved in $2 \times$ sodium dodecyl sulfate (SDS) loading buffer, and boiled at $100{ }^{\circ} \mathrm{C}$. After $5 \mathrm{~min}$, the samples were subjected to $10 \%$ SDS-polyacrylamide gel electrophoresis. The separated protein was transferred onto a polyvinylidene fluoride membrane, which was blocked using $5 \%$ skim milk powder at room temperature for $1 \mathrm{~h}$. The membrane was incubated with the diluted primary antibodies to $\beta$-actin (ab8226, 1:1000), CD63 (ab216130, 1:5000), TSG101 (ab83, 1:5000), calnexin (ab22595, 1:5000) ADIPOQ (ab22554, 1:1000), cKIT (ab32363, 1:1000), CD44 (ab189524, 1:1000), and CD24 (ab179821, 1:1000). All antibodies were purchased from Abcam Inc. (Cambridge, UK). Next, the membrane was incubated with the horseradish peroxidase-labeled secondary antibody for $1 \mathrm{~h}$. The protein bands were visualized using the enhanced chemiluminescence fluorescence detection kit (Cat. No. BB-3501, Amersham, Little Chalfont, Buckinghamshire, UK). The images were captured with a gel imager and photographed by a Bio-Rad Image Analysis System (Bio-Rad, Hercules, CA, USA), followed by quantitation with the Quantity One v4.6.2 software. The relative protein expression was expressed as the gray value of the corresponding protein band/the gray value of the $\beta$-actin protein band. The experiment was conducted 3 times independently.

\section{Cell counting kit-8 (CCK-8) assay}

MCF-7 cells in the logarithmic growth phase were detached using $2.5 \mathrm{~g} / \mathrm{L}$ trypsin. DMEM complete medium was added to prepare the single cell suspension, which was inoculated into the 96 -well plates at $5 \times 10^{3}$ cells/mL, followed by overnight incubation with $\mathrm{CO}_{2}$ at $37{ }^{\circ} \mathrm{C}$. TAM at different concentrations was added for subsequent incubation of $48 \mathrm{~h}$. A total of $10 \mu \mathrm{L}$ freshly prepared CCK- 8 solution (Dojdo, Kumamoto, Japan) was added to $100 \mu \mathrm{L}$ of the incomplete medium and incubated for $4 \mathrm{~h}$ at $37^{\circ} \mathrm{C}$. The optical density (OD) value was measured at an excitation wavelength of $450 \mathrm{~nm}$ using a scanning spectrophotometer (Bio-Rad, Hercules, CA, USA). With the TAM concentration plotted on the $x$-axis and the $\mathrm{OD}_{450}$ value plotted on the y-axis, the growth curves of the cells were plotted. Besides, the difference in the half maximal inhibitory concentration $\left(\mathrm{IC}_{50}\right)$ caused by TAM was calculated. All experiments were conducted three times independently.

\section{Annexin-V-fluorescein isothiocyanate (FITC)/propidium iodide (PI) double staining assay}

MCF-7 cells in the logarithmic growth phase were seeded in six-well plates (approximately $5 \times 10^{4}$ cells/well). After observing the adherence of cells to the wells, the cells were incubated with TAM of $\mathrm{IC}_{50}$ concentration for $24 \mathrm{~h}$. The floating cells in the supernatant and the cells that adhered to the wells under normal growth were collected by centrifugation. The cell pellet was resuspended using $1 \times$ binding buffer and incubated with $5 \mu \mathrm{L}$ Annexin-VFITC and $10 \mu \mathrm{L}$ PI for $15 \mathrm{~min}$ at room temperature in 
conditions devoid of light. The apoptosis rate was measured using a flow cytometer. Annexin-V-FITC positive cells represented early apoptosis, and the cells positive for both Annexin-V-FITC and PI represented advanced apoptosis. The experiment was conducted three times independently.

\section{PI staining for cell cycle}

MCF-7 cells in the logarithmic growth phase were seeded in six-well plates at approximately $5 \times 10^{4}$ cells/well. After observing the adherence of the cells to the well, the cells were incubated with TAM of $\mathrm{IC}_{50}$ concentration for $72 \mathrm{~h}$. A single cell suspension of the MCF-7 cells was then prepared by detachment and was fixed overnight at $-20{ }^{\circ} \mathrm{C}$ in $1 \mathrm{~mL}$ of pre-cooled $75 \%$ alcohol. Then, PI and RNase were added for 30 -min incubation at $37{ }^{\circ} \mathrm{C}$ in conditions devoid of light. A flow cytometer was used to detect the cell cycle distribution. The experiment was conducted three times independently.

\section{Quantification of gene expression}

The Trizol method (Cat. No. 16096020, Thermo Fisher Scientific Inc., Waltham, MA, USA) was employed to extract the total RNA content. Then $5 \mu \mathrm{g}$ of the total RNA content was reverse transcribed into cDNA using a quantitative real-time polymerase chain reaction (qRT-PCR) kit (ABI Company, Oyster Bay, N.Y., USA) according to the provided instructions. Reverse transcription and quantification of miRNA were performed using the miScript II RT kit (218161, QIAGEN, GmbH, Hilden, Germany) and the miScript SYBR Green PCR kit (218075, QIAGEN, GmbH, Hilden, Germany). The primer sequences of miR-9-5p, U6, ADIPOQ, and $\beta$-actin are presented in Table 1. U6 was adopted as the internal reference for miR-9-5p, while $\beta$-actin was adopted for other genes. The ratio of the expression of the target gene in the experimental group to that in the control group was estimated based on the $2^{-\Delta \Delta C t}$ method. The experiment was conducted three times independently.

\section{Microarray analysis}

$\mathrm{BC}$-related gene expression profiles were retrieved from the Gene Expression Omnibus (GEO) database (https://

Table 1 Primer sequences for qRT-PCR

\begin{tabular}{lll}
\hline Gene & Forward $\left(\mathbf{5}^{\prime} \mathbf{- \mathbf { 3 } ^ { \prime }}\right)$ & Reverse $\left(\mathbf{5}^{\prime} \mathbf{-} \mathbf{3}^{\prime}\right)$ \\
\hline miR-9-5p & GTGCAGGGTCCGAGGT & GCGCTCTTTGGTTATCTAGC \\
U6 & AAAGCAAATCATCGGACGACC & $\begin{array}{c}\text { GTACAACACATTGTTTCC } \\
\text { TCGGA }\end{array}$ \\
ADIPOQ & TGTGTGTGTGGGGTCTGTCT & TGTGATGAAAGAGGCCAGAA \\
B-actin & GCACCACACCTTCTACAATG & TGCTTGCTGATCCACATCTG \\
\hline
\end{tabular}

www.ncbi.nlm.nih.gov/geo/). The differential expression analysis was performed using the $\mathrm{R}$ language "limma" package, with $\mid \log$ foldchange $(\mathrm{FC}) \mid>2$ and $p$ value $<0.05$ as the outlining criteria to identify the differentially expressed genes (DEGs). A heat map of DEGs was constructed using the "pheatmap" package. The "clusterprofiler" package in the $\mathrm{R}$ language was employed for enrichment analysis of the metabolic pathways in the Kyoto Encyclopedia of Genes and Genomes (KEGG). A protein-protein interaction network was constructed using the String database (https://string-db.org). Regulatory miRNAs of ADIPOQ were predicted using a combination of the mirDIP database (http://ophid.utoronto. $\mathrm{ca} / \mathrm{mirDIP} /$ index.jsp\#r), the microRNA database (http:// www.microrna.org/microrna/home.do?tdsourcetag=s pcqq_aiomsg), the miRmap database (https://mirmap. ezlab.org), and the TargetScan database (http://www. targetscan.org/vert_71/).

\section{Luciferase activity assay}

The $3^{\prime}$ untranslated region ( $3^{\prime} \mathrm{UTR}$ ) of the ADIPOQ gene was cloned with CDNA of the MCF7 cells as a template. Based on the binding site of miR-9-5p and ADIPOQ $3^{\prime}$ UTR predicted by TargetScan, a site-directed mutagenesis was performed for the corresponding site. The $3^{\prime}$ UTR wild-type (WT) was used as a template to construct an ADIPOQ $3^{\prime} \mathrm{UTR}$ reporter vector with mutation. The ADIPOQ-mutant (MUT) was constructed using the QuikChange Site-Directed Mutagenesis Kit (Stratagene, La Jolla, CA, USA). The mutation of miR-9-5p recognizing the ADIPOQ $3^{\prime} \mathrm{UTR}$ site sequence ACCAAAG was TGGTTTC. The primer sequences were recombined into the pNL1.1 vector (Promega, Madison, WI, USA) to transfect an amplified recombinant plasmid vector in Escherichia coli DH5 $\alpha$. The pRL-TK vector expressing Renilla luciferase was adopted as an internal reference to adjust the difference in cell number and transfection efficiency. The miR-9-5p mimic and miR-9-5p mimicNC (4464084, ABI, Foster City, CA, USA) were co-transfected into the $293 \mathrm{~T}$ cells with a dual luciferase reporter vector. The dual luciferase activity assay was performed in strict accordance with the instructions provided by Promega (Madison, WI, USA). Each experiment was conducted three times independently.

\section{Subcutaneous tumor formation in nude mice}

In total, 40 female nude mice (4-5 weeks old) were injected subcutaneously with $1.5 \mathrm{mg} / \mathrm{kg}$ estradiol cetylpropionate 3 days prior to tumor implantation, after which they were injected once a week. All nude mice were housed in a specific pathogen free environment. Once cell confluence reached 70\%, the MCF7 cells were detached, centrifuged, and suspended in PBS to isolate 
a cell suspension $\left(1 \times 10^{8}\right.$ cells $\left./ \mathrm{mL}\right)$. After anesthetizing the nude mice with $0.1 \%$ pentobarbital, the skin was incised along the third breast pad on the left side and dissected to the position of the breast pad. A total of $100 \mu \mathrm{L}$ of the cell suspension was injected into the breast pad, after which the incision was sutured. After the tumor grew to $200 \mathrm{~mm}^{3}$, the nude mice were assigned into 5 groups: group 1: $\mathrm{PBS}$; group 2: (MCF-7/TAM+miR9-5p Inhibitor)-exo (exosomes extracted from MCF-7/ TAM cells transfected with miR-9-p inhibitor); group 3: (MCF-7/TAM + miR-9-5p inhibitor-NC)-exo (exosomes extracted from MCF-7/TAM cells transfected with miR-9-5p inhibitor-NC); group 4: (MCF-7+ miR-9-5p mimic)-exo (exosomes of MCF-7 cells transfected with miR-9-5p mimic); group 5: (MCF-7 + miR-9-5p mimicNC)-exo (exosomes of MCF-7 cells transfected with miR-9-5p mimic-NC). The transfected exosomes were injected for 7 times with an interval of 3 days into the tumor. TAM $(20 \mathrm{mg} / \mathrm{kg})$ or PBS was intragastrically administered into the nude mice twice a week, starting from the first injection of exosomes. Twenty-one days later, the nude mice were euthanized, and the tumor tissue was harvested. The tumors were measured and photographed. Subsequently, a proportion of the tumor was stored in liquid nitrogen, and the remaining tumor pieces and other organs were immersed in $4 \%$ paraformaldehyde overnight to prepare the wax blocks for immunohistochemistry. Tumor volume (V) was calculated with the measured length (L) and width (W) according to the following formula: $\mathrm{V}=\left(\mathrm{LW}^{2}\right) / 2$.

\section{Immunohistochemistry}

Paraffin-embedded sections (4- $\mu \mathrm{m}$ in thickness) were dewaxed and subjected to ethylenediaminetetraacetic acid antigen repair. The sections were incubated with $3 \%$ $\mathrm{H}_{2} \mathrm{O}_{2}$ for $10 \mathrm{~min}$ at room temperature in order to terminate endogenous peroxidase activity and probed with antibody to ADIPOQ (ab22554, 1:1000, Abcam, Boston, MA, USA) at $4{ }^{\circ} \mathrm{C}$ overnight. The secondary antibody was added in a drop-wise manner and incubated at $37^{\circ} \mathrm{C}$ for $20 \mathrm{~min}$. After staining with 3,3'-diaminobenzidine (DAB), the sections were counterstained, dehydrated, permeabilized, and sealed.

\section{Terminal dUTP nick-end labeling (TUNEL) assay}

The sections were dewaxed and hydrated. Five sections were incubated with $50 \mu \mathrm{L}$ of $1 \%$ proteinase $\mathrm{K}$ in a $37{ }^{\circ} \mathrm{C}$ incubator for $30 \mathrm{~min}$. Methanol containing $0.3 \% \mathrm{H}_{2} \mathrm{O}_{2}$ was added to terminate endogenous peroxidase (POD) activity. TUNEL solution was added for incubation of the cells, in a humid chamber at $37{ }^{\circ} \mathrm{C}$ for $1 \mathrm{~h}$ in conditions devoid of light. Next, the cells were incubated with $50 \mu \mathrm{L}$ Converter-POD at $37^{\circ} \mathrm{C}$ for $30 \mathrm{~min}$. Color development was conducted using $2 \% \mathrm{DAB}$ with incubation for $15 \mathrm{~min}$ at room temperature. On appearance of brownish-yellow nuclei in the cells, the reaction was terminated using distilled water. After hematoxylin counterstaining, the sections were dehydrated, permeabilized using xylene, and sealed with neutral balsam. The cells were observed under an optical microscope.

\section{Three-dimensional (3-D) culture of MCF7 cells}

MCF-7 cells were cultured as 3-D spheroids as described previously [19]. MCF-7 cells $\left(3 \times 10^{4}\right)$ were incubated with the Matrigel (BD Biosciences, USA) that was added with DMEM/F12 containing 5\% horse serum (GIBCO, USA), epidermal growth factor (EGF, $20 \mathrm{ng} / \mathrm{mL}$ ), and $100 \mathrm{IU} / \mathrm{mL}$ penicillin/streptomycin under the condition of $5 \% \mathrm{CO}_{2}$ and $37{ }^{\circ} \mathrm{C}$. The Matrigel and DMEM/F12 was added every second day. The MCF7 cells were incubated with exosomes for $48 \mathrm{~h}$ and then were suspended at 1,10 , 100,1000 , and 10,000 cells/well. Sphere-forming ability was observed.

\section{Statistical analysis}

All the data were processed using the SPSS 21.0 statistical software (IBM Corp, Armonk, NY, USA). The measurement data were expressed by mean \pm standard deviation. The $t$ test was adopted to compare paired data with normal distribution and equal variance between two groups. Unpaired data with normal distribution and equal variance were compared between two groups using the unpaired $t$ test. Data comparison between multiple groups was performed using one-way analysis of variance (ANOVA) followed by the Tukey's post hoc test. Data comparison between groups at different time points was performed by repeated measurement ANOVA with a Bonferroni's post hoc test. In all statistical references, a value of $p<0.05$ was indicative of a statistically significant difference.

\section{Results}

\section{Exosomes from MCF-7/TAM cells can be transferred into the parental MCF-7 cells}

In order to examine the influence of exosomes on the drug resistance in $\mathrm{BC}$ cells, the exosomes were firstly isolated from the culture supernatant of MCF-7 cells and MCF-7/TAM cells and subsequently identified. TEM observation demonstrated the presence of round membrane-bound vesicles with a diameter of 30-100 nm (Fig. 1a). Observation of NanoSight NS300 indicated that isolated exosomes ranged from 60 to $120 \mathrm{~nm}$ and the concentration of exosomes in MCF-7 and MCF-7/TAM cells were $4.27 \times 10^{12}$ particle $/ \mathrm{ml}$ and $4.43 \times 10^{12}$ particle/ $\mathrm{mL}$, respectively (Fig. 1b). Western blot analysis verified the expression of marker proteins CD63 and TSG101 in 

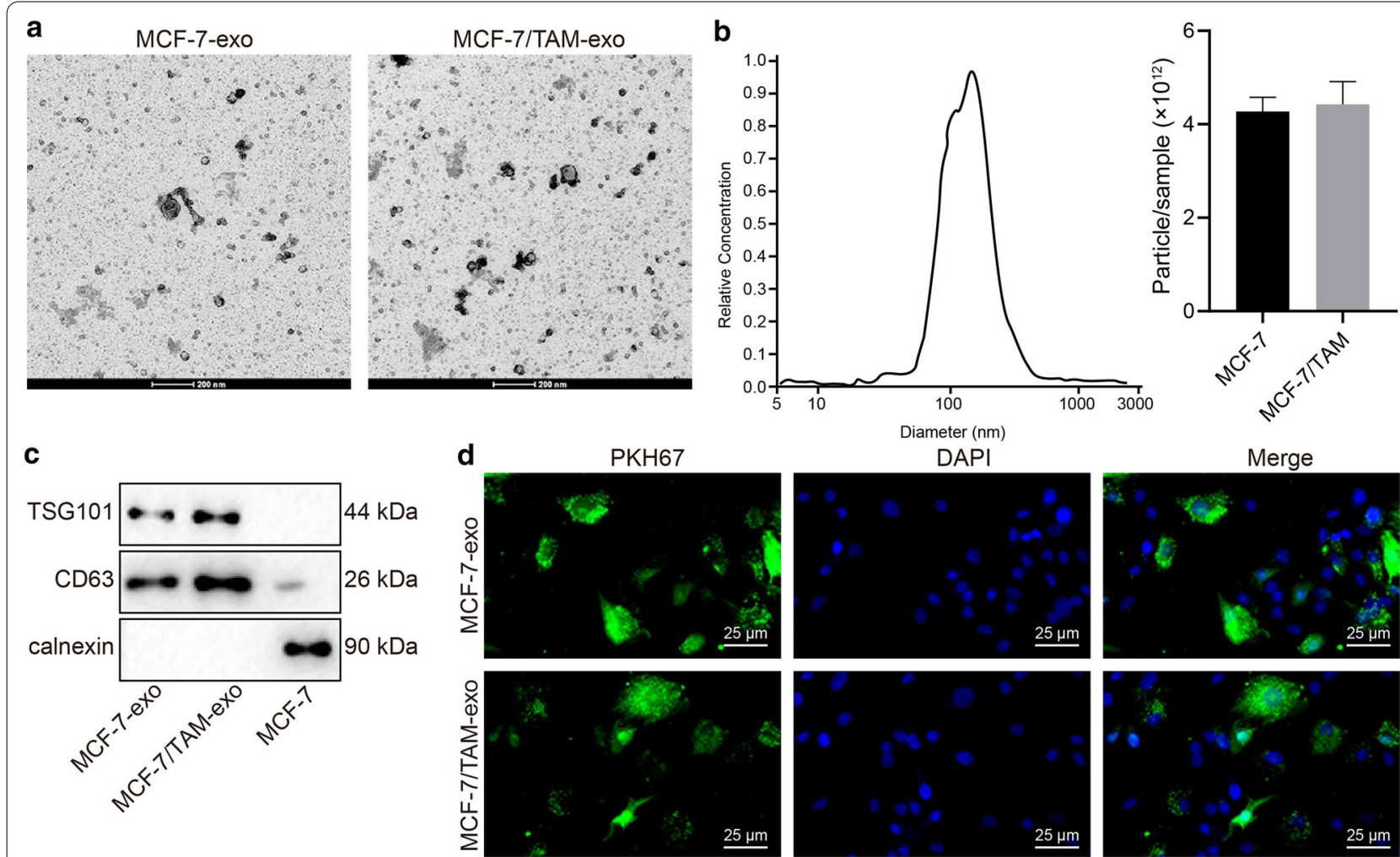

Fig. 1 Exosomes from MCF-7/TAM cells can be transferred into the parental MCF-7 cells. a TEM observation of exosomes (scale bar: $200 \mathrm{~nm}$ ). b Nanoparticle tracking analysis of exosome concentration and size. $\mathbf{c}$ The expression patterns of marker proteins (CD63 and TSG101) of exosomes in MCF-7-exo and MCF-7/TAM-exo detected by Western blot analysis (normalized to $\beta$-actin). $\mathbf{d}$ MCF-7-exo and MCF-7/TAM-exo (labeled with PKH67 dye) could be internationalized by parental MCF-7 cells (scale bar: $25 \mu \mathrm{m}$ )

the exosomes (Fig. 1c). To investigate whether MCF-7/ TAM-exo can be delivered to the sensitive cells and affect the resistant phenotype of sensitive cells, the MCF-7-exo and MCF-7/TAM-exo were co-cultured in the sensitive cells (MCF-7 cells) for $24 \mathrm{~h}$. The results showed the capacity of sensitive cells to uptake exosomes from the Tamoxifen resistant cells (labeled by PKH67 staining) (Fig. 1d).

\section{Exosomes from MCF-7/TAM cells confers drug resistance in the parental MCF-7 cells}

CCK-8 assay (Fig. 2a, b) was conducted to evaluate whether MCF-7/TAM-exo increased the resistance of MCF-7 cells to TAM. MCF-7 cells were treated with PBS, MCF-7-exo or MCF-7/TAM-exo for 9 days, each, after which TAM of variable concentrations was added. After $72 \mathrm{~h}$ of culture, the OD value was measured using a microplate reader, after which the cell viability curve was plotted. In comparison to treatment with PBS and MCF-7-exo, the cell viability of MCF-7 cells co-cultured with MCF-7/TAM-exo was significantly enhanced and $\mathrm{IC}_{50}$ was significantly elevated under TAM treatment $(p<0.05)$. Besides, flow cytometry was conducted to detect the cell cycle distribution (Fig. 2c) of MCF7 cells co-cultured with exosomes and the apoptosis rate (Fig. 2d) after $10 \mu \mathrm{M}$ of TAM treatment, so as to assess that the drug resistance conferred. Relative to the treatment of PBS and MCF-7-exo, the MCF-7 cells co-cultured with MCF-7/TAM-exo demonstrated an increased number of cells in the G1 phase and a decreased number of cells in the $S$ phase $(p<0.05)$, accompanied by a reduced apoptotic rate $(p<0.05)$. We examined the effects of MCF-7/TAM-exo on the stemness of MCF-7 cells. It revealed that MCF-7/TAM-exo promoted the stemness of MCF-7 cells as evidenced by increased expressions of stemness markers cKIT, CD44, and CD24 when comparable to PBS and MCF-7-exo (Fig. 2e). Accordingly, results of 3-D cell culture displayed that MCF-7/TAMexo enhanced sphere-forming abilities of MCF-7 cells when comparable to PBS and MCF-7-exo (Fig. 2f). These results indicate that MCF-7/TAM-exo could increase the resistance of MCF-7 cells to TAM. 

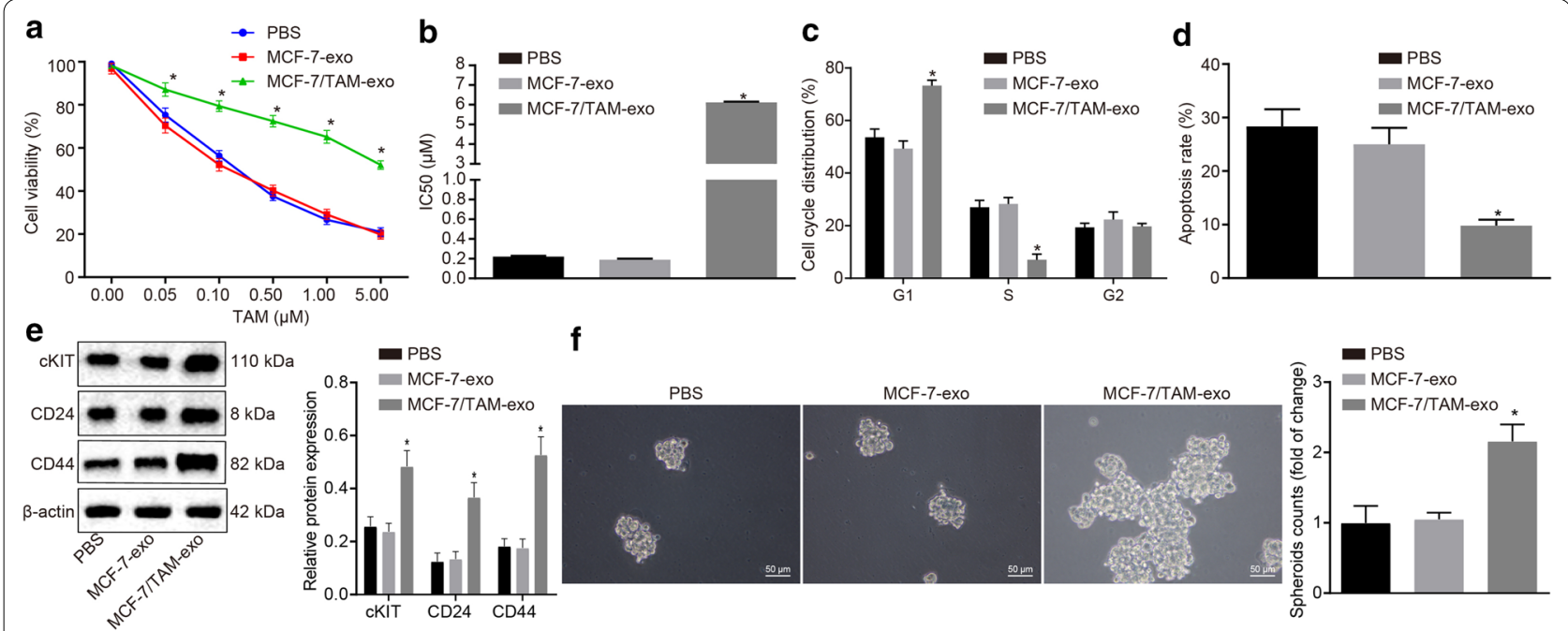

f
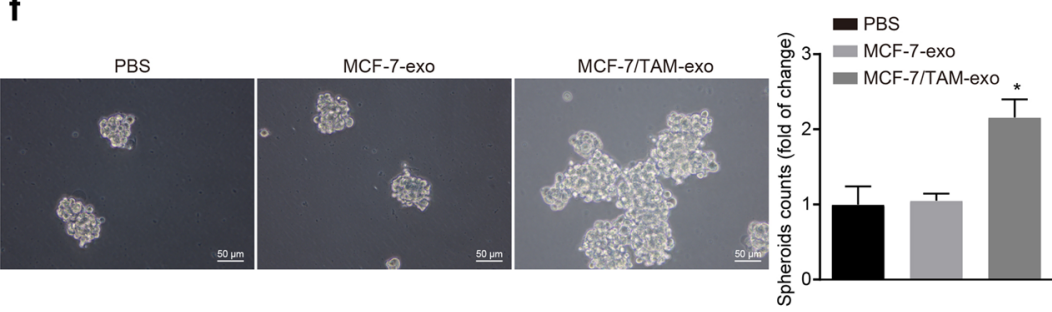

Fig. 2 Exosomes from MCF-7/TAM cells confers drug resistance in the parental MCF-7 cells. a The cell viability of MCF-7 cells after TAM treatment determined by CCK-8. $\mathbf{b} \mid \mathrm{C}_{50}$ values of MCF-7 cells treated with TAM. $\mathbf{c}$ The cell cycle distribution of MCF-7 in the presence of MCF-7/TAM-exo, analyzed by flow cytometry. $\mathbf{d}$ The apoptosis of MCF-7 cells in the presence of MCF-7/TAM-exo, analyzed by flow cytometry. e Western blot analysis of stemness markers KIT, CD44, and CD24 in MCF-7 cells in the presence of MCF-7/TAM-exo. f Sphere-forming abilities of MCF-7 cells in the presence of MCF-7/TAM-exo were examined by 3-D cell culture (scale bar: $50 \mu \mathrm{m}$ ). ${ }^{*} p<0.05$. All experiments were conducted three times independently

\section{Microarray-based analysis identifies ADIPOQ and miR-9-5p as the study subjects}

In order to identify the genes involved in the effect of exosomes on the drug resistance of $\mathrm{BC}$ cells, we explored the GEO database to retrieve the $\mathrm{BC}$-related expression profile GSE61304, which consisted of 4 normal samples and 58 BC samples. Differential analysis of gene expression in the $\mathrm{BC}$ samples and normal control samples in this expression profile was performed, which identified 176 DEGs (Fig. 3a). Functional enrichment analysis revealed that the DEGs were principally enriched in several KEGG signaling pathways like the PPAR signaling pathway, which elicited the highest enrichment level (Fig. 3b). Besides, the corresponding DEGs in the PPAR signaling pathway were subjected to protein-protein interaction analysis, which revealed that ADIPOQ, FABP4, and PLIN1 were the core genes (Fig. 3c). Therefore, the significant functions of these three genes were retrieved, which showed that ADIPOQ could negatively regulate tumor growth [18] and was associated with the therapeutic effects of TAM [20]. In order to further investigate the upstream regulatory mechanism of ADIPOQ, the regulatory miRNAs of ADIPOQ were predicted using multiple bioinformatic databases such as TargetScan and the intersecting results were determined (Fig. 3d) to classify 20 miRNAs as common. Among them, miR-9-5p was evidently carried by exosomes and thus exerted effects $[21,22]$. These results and findings suggest that miR-9-5p, via the delivery of exosomes, might target and regulate ADIPOQ to influence the effects of TAM on BC.

\section{ADIPOQ is a target gene of miR-9-5p}

The binding site between miR-9-5p and ADIPOQ was predicted using the biological prediction website TargetScan (http://www.targetscan.org) (Fig. 4a). The dual luciferase reporter assay was adopted to ascertain ADIPOQ as a target of miR-9-5p. In response to the sitedirected mutagenesis on the binding sites of miR-9-5p and ADIPOQ-WT, the luciferase activity of $293 \mathrm{~T}$ cells in the miR-9-5p mimic and ADIPOQ-WT co-transfection group had decreased by $50 \%(p<0.05)$, while no significant changes were observed in the luciferase activity in the miR-9-5p mimic and ADIPOQ-MUT transfection group (Fig. 4b). This result indicates that miR-9-5p can directly regulate the ADIPOQ gene. Simultaneously, we further verified the results by transfecting miR-9-5p mimic and inhibitor into the MCF-7 or MCF-7/TAM cells. After transient transfection of miR-9-5p mimic in the MCF-7 cells, the miR-9-5p expression pattern was significantly increased (Fig. 4c, $p<0.05)$, while the mRNA and protein expression patterns of ADIPOQ were significantly reduced (Fig. $4 \mathrm{~d}$, e, $p<0.05)$, as compared to mimic-NC. After transient transfection of miR-9-5p inhibitor in the MCF-7/TAM cells, the expression pattern of miR-9-5p was significantly decreased (Fig. 4c, $p<0.05$ ), while the mRNA and protein expression patterns of ADIPOQ were 


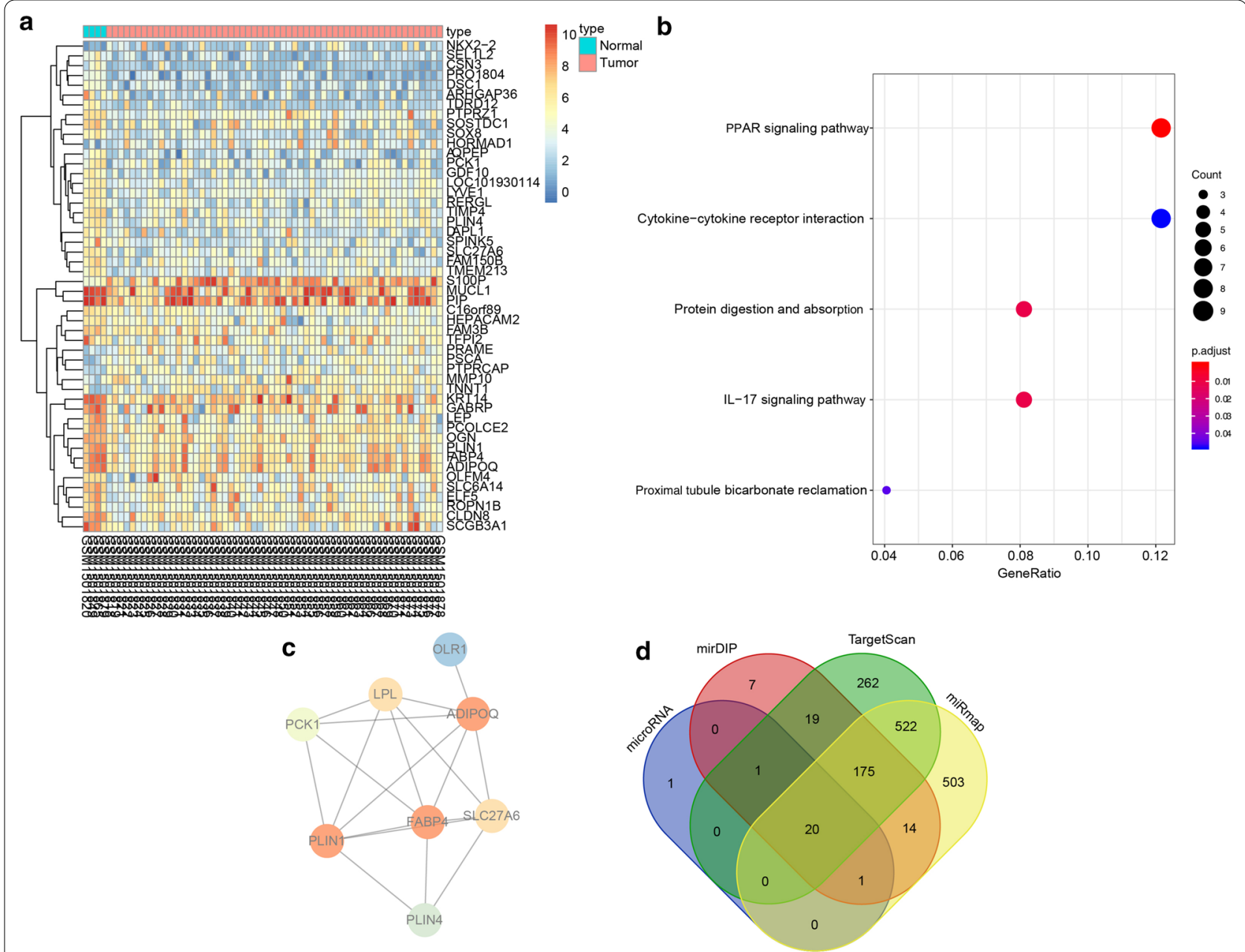

Fig. 3 ADIPOQ and miR-9-5p is involved in the drug resistance of BC. a Heat map of BC-related DEGs in different expression profiles. The x-axis indicates the sample number, the $y$-axis indicates the gene name, and the left dendrogram indicates the gene expression cluster. Each small square in the panel indicates the expression of a gene in one sample. $\mathbf{b}$ Enrichment analysis of DEGs in KEGG metabolic pathways. The $x$-axis refers to GeneRatio, the $y$-axis refers to KEGG signaling pathways, and the right histogram represents color gradation. $\mathbf{c}$ Protein-protein interaction network of the DEG in the PPAR signaling pathway. Each circle represents a gene and the circle color represents the core degree of the DEG in the interaction network. Darker color means higher core degree. $\mathbf{d}$ Prediction of upstream regulatory miRNAs of ADIPOQ. Four ellipses refer to the results predicted from the four databases and the central section refers to the intersecting of the prediction results

considerably increased (Fig. 4 d, e, $p<0.05$ ), as compared to inhibitor-NC. The results indicated that the expression pattern of miR-9-5p could be effectively regulated in the cells by transient transfection of miR-9-5p mimic or miR-9-5p inhibitor, and miR-9-5p targeted and regulated the expression pattern of ADIPOQ.

\section{MiR-9-5p promotes TAM resistance in the parental MCF-7 cells}

To further investigate the role of miR-9-5p in BC cell resistance, the expression pattern of miR-9-5p in the MCF-7 and MCF-7/TAM cells was examined. The expression pattern of miR-9-5p was significantly increased in the MCF-7/TAM cells (Fig. 5a, $p<0.05$ ). We further conducted experiments to determine sensitivity of the transfected cells, with diluted TAM at different concentrations for treatment of the transfected cells for $48 \mathrm{~h}$. The OD value of the transfected cells was detected using a CCK-8 kit, and the $\mathrm{IC}_{50}$ value of cells was calculated using the SPSS software. In comparison with mimic-NC, the transient transfection of miR-9-5p mimic in MCF-7 cells decreased the cell inhibition rate, accompanied by increased $\mathrm{IC}_{50}(p<0.05)$, along with a decreased inhibition rate in a dose-dependent manner (Fig. 5b, c). In consistency, the transient transfection of miR-9-5p inhibitor in MCF-7/TAM cells exercised 


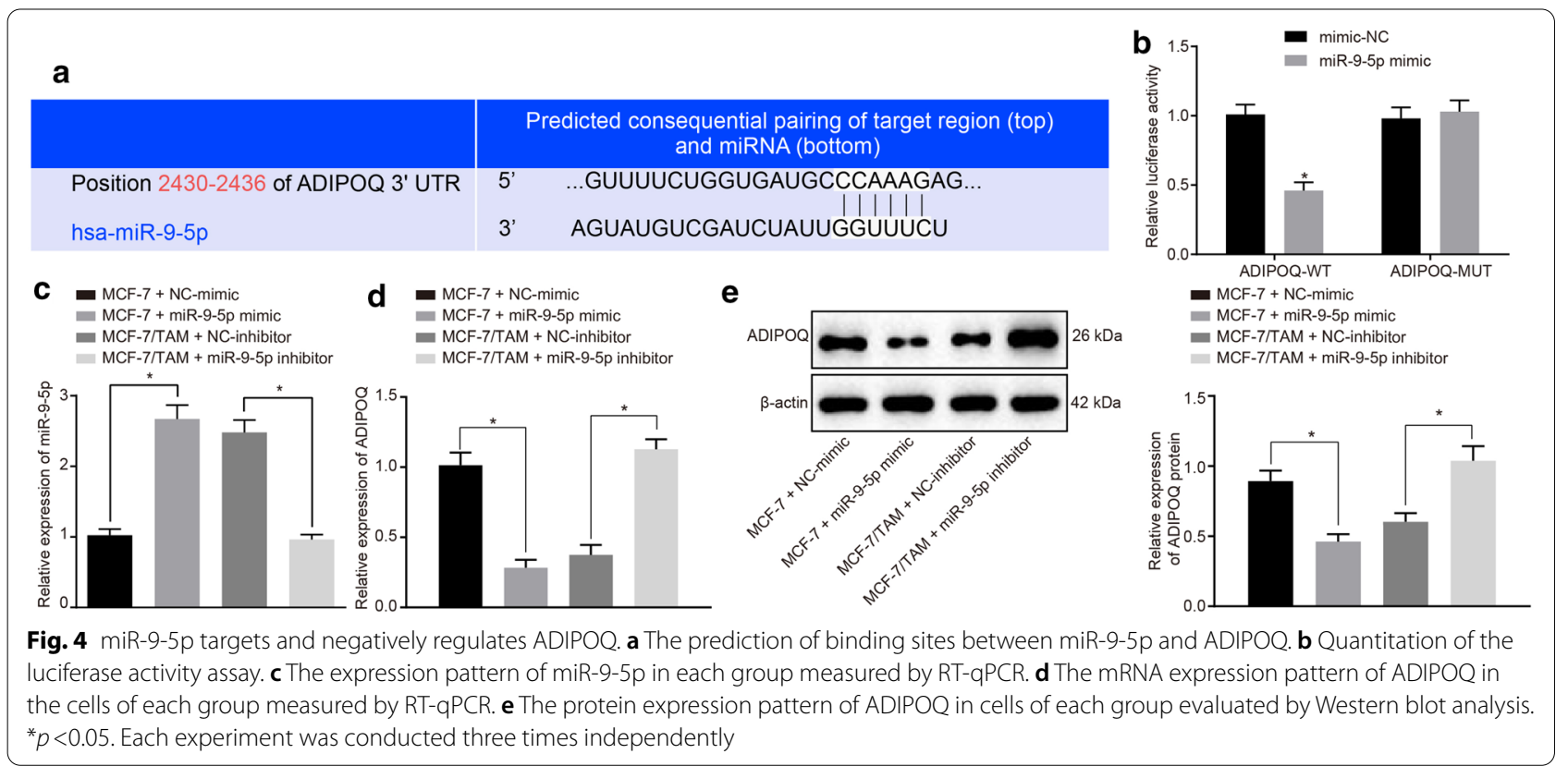
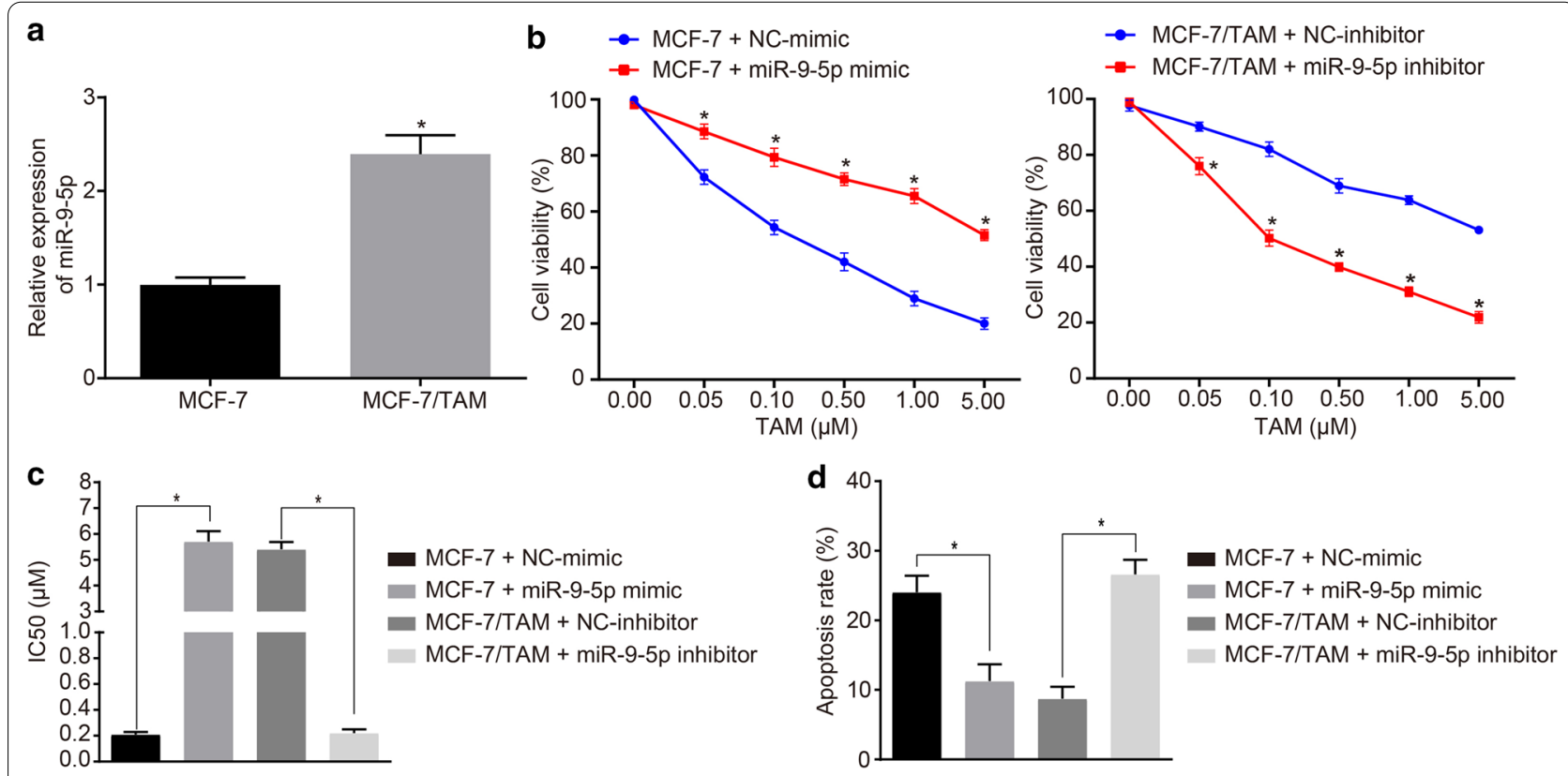

Fig. 5 MiR-9-5p promotes TAM resistance in the parental MCF-7 cells. a The miR-9-5p expression in MCF-7 and MCF-7/TAM cell lines measured by RT-qPCR. $\mathbf{b}$ The cell viability of cells in response to miR-9-5p mimic or miR-9-5p inhibitor determined by CCK-8. c Quantitation of $I C_{50}$ value of cells in response to miR-9-5p mimic or miR-9-5p inhibitor. $\mathbf{d}$ Flow cytometric detection of apoptosis rate of cells transfected with miR-9-5p mimic or miR-9-5 $p$ inhibitor. ${ }^{*} p<0.05$. Each experiment was conducted three times independently

conflicting results $(p<0.05$; Fig. $5 \mathrm{~b}, \mathrm{c})$. To investigate the effect of miR-9-5p on the apoptosis of MCF-7 cell line, flow cytometry was adopted. After transient transfection of miR-9-5p mimic into the MCF-7 cells, the apoptosis rate of cells was significantly reduced as compared to mimic-NC (Fig. $5 \mathrm{~d}, p<0.05$ ). In the presence of transient transfection of miR-9-5p inhibitor, the cell apoptosis rate was significantly elevated relative to the 
inhibitor-NC (Fig. 5d, $p<0.05$ ). The aforementioned results indicated that miR-9-5p could inhibit MCF-7 cells apoptosis and promote drug resistance.

\section{Exosomes carrying miR-9-5p down-regulates the expression of ADIPOQ in BC cells}

To validate whether exosomal miR-9-5p mediated the resistance by the regulation of ADIPOQ expression, we delivered the miR-9-5p mimic and inhibitor into the isolated exosomes from the MCF-7 and MCF-7/TAM cells followed by co-culture with the MCF-7 cells, in order to verify whether exosomes affect $\mathrm{BC}$ cells by carrying miR-9-5p.

As shown in Fig. 6a, the expression pattern of miR9-5p in (MCF-7 + miR-9-5p mimic)-exo was significantly higher compared to that of (MCF-7 + NC-mimic)-exo $(p<0.05)$. The miR-9-5p expression pattern of (MCF-7/ TAM + miR-9-5p inhibitor)-exo was lower than that of (MCF-7/TAM + NC-inhibitor)-exo $(p<0.05)$. Conjointly, the results suggested that exosomes could transfer miR-9-5p. After co-culture of these exosomes with MCF-7 cells, the expression pattern of miR-9-5p and ADIPOQ in the recipient MCF-7 cells were measured. Increased miR-9-5p expression and reduced mRNA and protein expression pattern of ADIPOQ were identified in the MCF-7 cells co-cultured with (MCF-7 + miR9-5p mimic)-exo, compared with the MCF-7 cells co-cultured with (MCF-7+ NC-mimic)-exo (Fig. 6b-d, $p<0.05)$. Moreover, after co-culture of MCF-7 cells with (MCF-7/TAM + miR-9-5p inhibitor)-exo, the expression pattern of miR-9-5p had reduced by $70 \%$, whereas the mRNA and protein expression patterns of ADIPOQ were elevated as compared to co-culture with (MCF-7/ TAM + NC-inhibitor)-exo (Fig. $6 \mathrm{~b}-\mathrm{d}, \quad p<0.05$ ). These results indicated that the transfection of miR-9-5p mimic and inhibitor into the MCF-7 and MCF-7/TAM-derived exosomes could effectively regulate the expression pattern of miR-9-5p in the recipient MCF-7 cells, accompanied by the regulation of ADIPOQ.

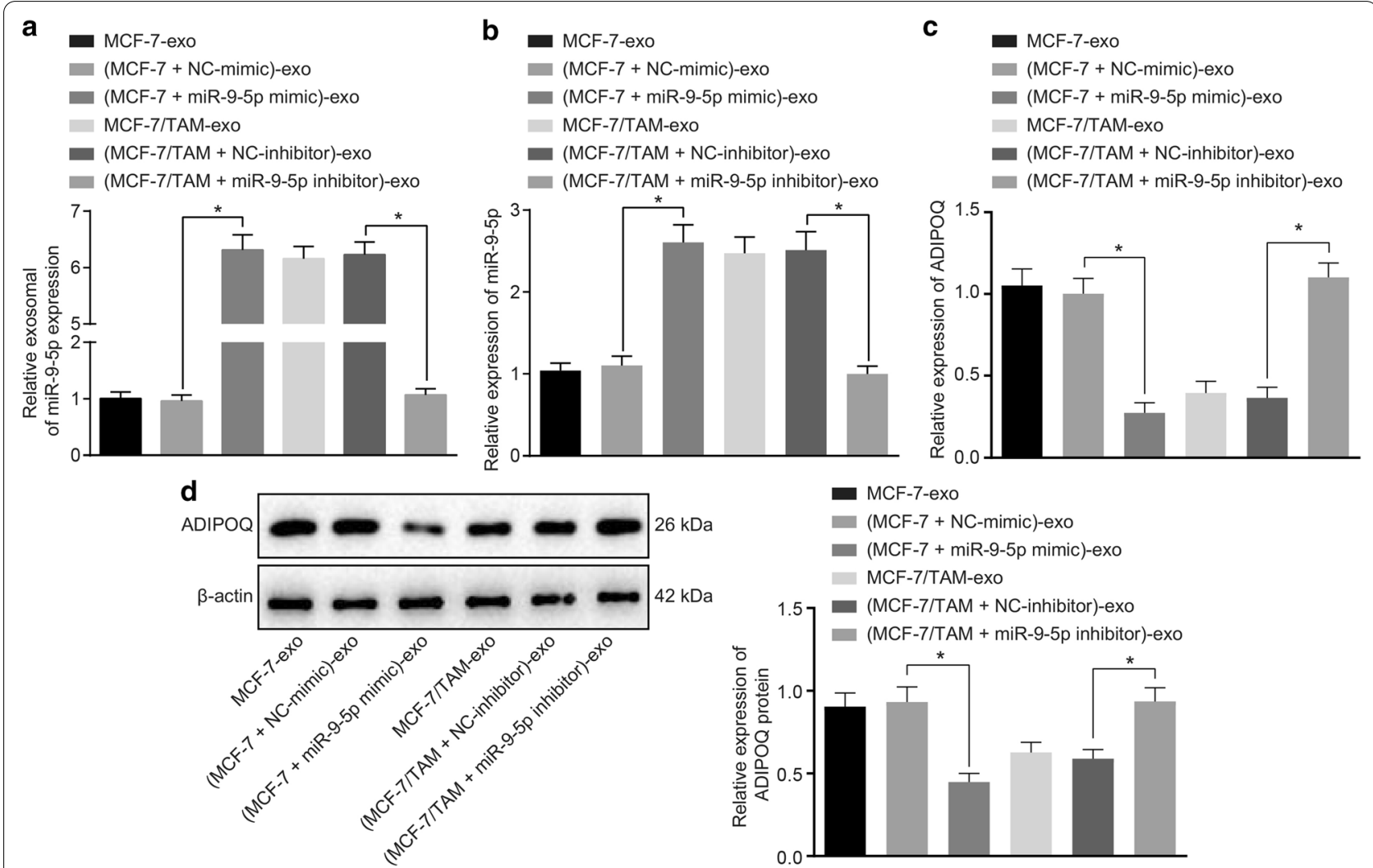

Fig. 6 Exosomes carrying miR-9-5p down-regulate the expression pattern of ADIPOQ in BC cells. a miR-9-5p expression in (MCF-7 + miR-9-5p mimic)-exo and (MCF-7/TAM + miR-9-5p inhibitor)-exo measured by RT-qPCR. $\mathbf{b}$ q expression pattern of miR-9-5p in the MCF-7 recipient cells after co-culture of (MCF-7 + miR-9-5p mimic)-exo or (MCF-7/TAM + miR-9-5p inhibitor)-exo measured by RT-qPCR. c The mRNA expression pattern of ADIPOQ in the MCF-7 recipient cells after co-culture of (MCF-7 + miR-9-5p mimic)-exo or (MCF-7/TAM + miR-9-5p inhibitor)-exo measured by RT-qPCR. $\mathbf{d}$ The protein expression pattern of ADIPOQ in the MCF-7 cells after co-culture of (MCF-7 + miR-9-5p mimic)-exo or (MCF-7/ TAM + miR-9-5p inhibitor)-exo evaluated by Western blot analysis. ${ }^{*} p<0.05$. Each experiment was conducted three times independently 
MiR-9-5p dictates drug resistance conferred by exosomes isolated from MCF-7/TAM cells in the parental MCF-7 cells

To further investigate the role of (MCF-7 + miR-9-5p mimic)-exo and (MCF-7/TAM + miR-9-5p inhibitor)exo in respect to drug resistance of $\mathrm{BC}$ cells, the sensitivity of MCF-7 cells with different transfections was strenuously evaluated. The MCF-7 cells elicited a reduced cell inhibition rate and increased $\mathrm{IC}_{50}$ after co-culture of (MCF-7 + miR-9-5p mimic)-exo, relative to the co-culture of (MCF-7 + NC-mimic)-exo (Fig. 7a, $\mathrm{b}, p<0.05)$, and the inhibition rate was abrogated in a dose-dependent manner (Fig. 7a). These results indicated that the up-regulation of exosomal miR-9-5p expression could improve the resistance of MCF-7 cells to TAM. Furthermore, the same procedure was adopted to examine the effect of miR-9-5p inhibitor on the sensitivity of MCF-7 cells to TAM. The MCF-7 cells co-cultured with (MCF-7/TAM + miR-9-5p inhibitor)-exo led to increased cell inhibition rate and reduced $\mathrm{IC}_{50}$ relative to the co-culture of (MCF-7/TAM + NC-inhibitor)exo (Fig. $7 \mathrm{a}, \mathrm{b}, p<0.05$ ), with the inhibition rate eliciting a dose-dependent relationship (Fig. 7a). These findings suggested that exosomes alter the sensitivity of MCF-7 cells to TAM by exosomal miR-9-5p. Meanwhile, flow cytometry was adopted to detect the apoptosis of the transfected cells. The MCF-7 cells co-cultured with (MCF-7 + miR-9-5p mimic)-exo exhibited a reduced apoptosis rate, as compared with (MCF-7+ NCmimic)-exo (Fig. 7c, $p<0.05$ ). After co-culture of MCF-7 cells with (MCF-7/TAM + miR-9-5p inhibitor)-exo, the apoptosis rate was increased as compared to (MCF-7/ $\mathrm{TAM}+\mathrm{NC}$-inhibitor)-exo (Fig. $7 \mathrm{c}, \quad p<0.05$ ). These results indicated the ability of exosomes to transfer miR-9-5p into the MCF-7 cells, and subsequent initiate the inhibition of apoptosis and promotion of drug resistance.

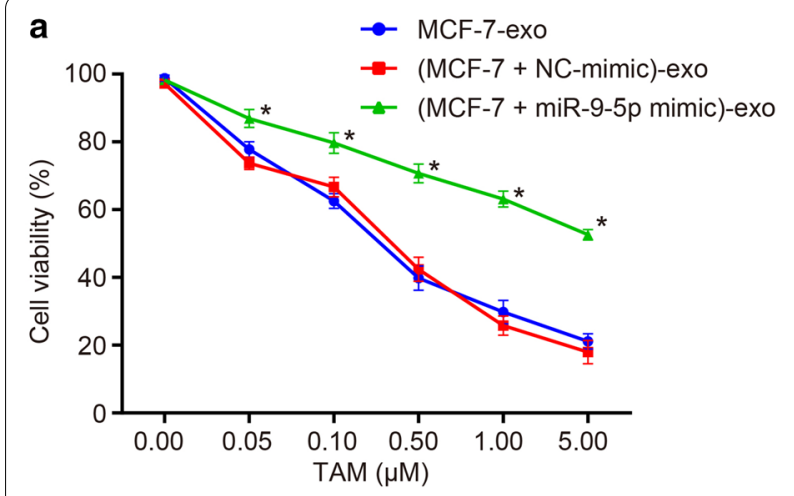

b
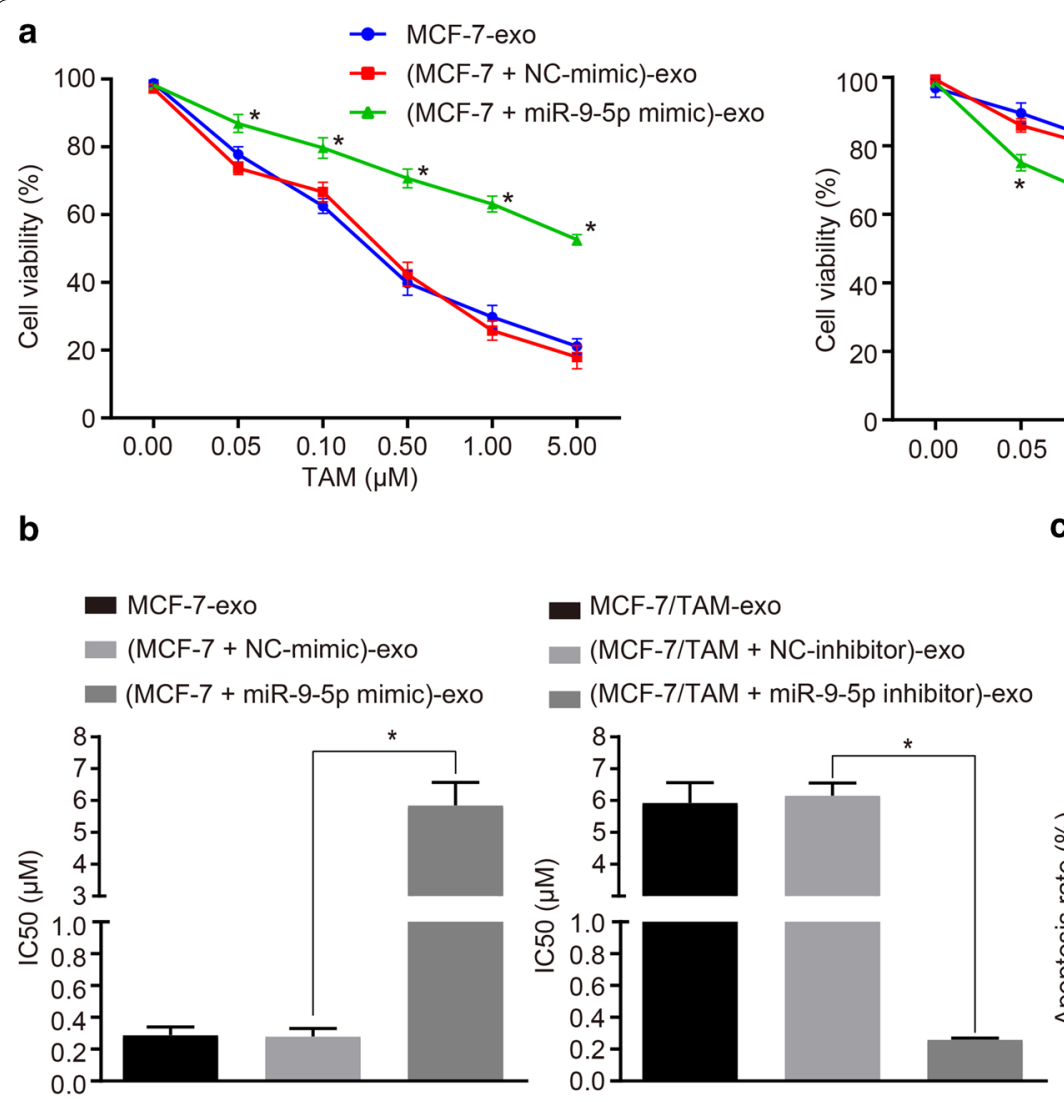

Fig. 7 MiR-9-5p dictates drug resistance conferred by exosomes isolated from MCF-7/TAM cells in the parental MCF-7 cells. a The viability of MCF-7 recipient cells after co-culture with (MCF-7 + miR-9-5p mimic)-exo or (MCF-7/TAM + miR-9-5p inhibitor)-exo determined by CCK-8. $\mathbf{b}$ The quantitation of $\mathrm{IC}_{50}$ of MCF-7 recipient cells after co-culture. $\mathbf{c}$ Flow cytometric detection of the apoptosis of MCF-7 recipient cells after co-culture with (MCF-7 + miR-9-5p mimic)-exo or (MCF-7/TAM + miR-9-5p inhibitor)-exo. ${ }^{*} p<0.05$. Each experiment was conducted three times independently 
MiR-9-5p dictates drug resistance conferred by exosomes isolated from MCF-7/TAM cells by regulating ADIPOQ in vivo

To further investigate the effect of exosomal miR-9-5p on tumor resistance to TAM in vivo, the MCF-7 orthotopic tumors implanted in the nude mice were ascertained. When the tumor grew to $100 \mathrm{~mm}^{3}$, the exosomes were injected into the tumors at multiple sites, once every 3 days, for a total of 7 trials. TAM was weekly administered intragastrically to simulate the standard administration process. The results showed that the tumor volume and weight of the nude mice injected with (MCF-7+ miR-9-5p mimic)-exo were significantly higher compared to those injected with (MCF-7 + NC-mimic)exo. Besides, the tumor volume and weight of the nude mice injected with (MCF-7/TAM + miR-9-5p inhibitor)exo were significantly lower than those with (MCF-7/ $\mathrm{TAM}+\mathrm{NC}$-inhibitor)-exo (Fig. $8 \mathrm{a}-\mathrm{c}$ ). TUNEL staining
(Fig. 8d) was employed so as to assess MCF-7 cell apoptosis. The results showed that the cell apoptosis in tumors of nude mice injected with (MCF-7 + miR-9-5p mimic)-exo was significantly reduced relative to those injected with (MCF-7 + NC-mimic)-exo. Besides, the cell apoptosis in tumors of nude mice injected with (MCF-7/ TAM + miR-9-5p inhibitor)-exo was significantly higher than those injected with (MCF-7/TAM + NC-inhibitor)exo. In addition, immunohistochemistry and Western blot analysis were employed to measure the protein expression patterns of ADIPOQ. ADIPOQ was predominantly expressed in the cytoplasm. The protein expression pattern of ADIPOQ in the tumors of nude mice injected with (MCF-7+miR-9-5p mimic)-exo was significantly lower than those injected with (MCF-7 + NC-mimic)exo. Besides, the expression pattern of the ADIPOQ protein in the tumors of nude mice injected with (MCF-7/ TAM + miR-9-5p inhibitor)-exo was significantly higher

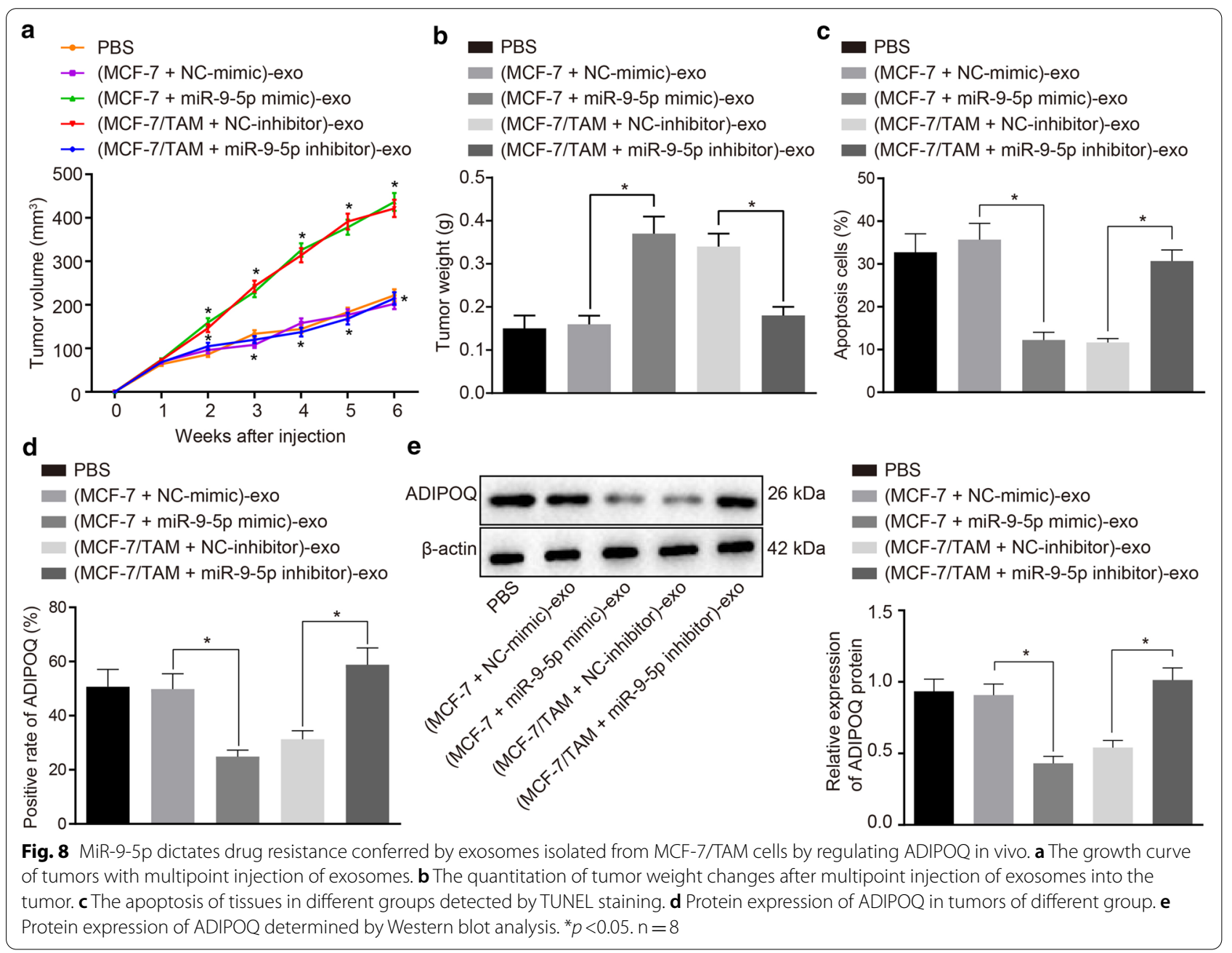


compared to those injected with (MCF-7/TAM + NCinhibitor)-exo (Fig. 8e, f). In summary, exosomal miR9-5p could evident inhibit the expression pattern of ADIPOQ in vivo and mediate tumor cell resistance to TAM.

\section{Discussion}

$\mathrm{BC}$ is one of the most frequently diagnosed fatal cancers and persists as the leading cause of cancer associated mortality amongst women [23]. TAM is commonly adopted for the treatment of $\mathrm{BC}$, however the drug resistance has been significant to unsatisfactory treatment outcomes $[8,24]$. Research has well established the ability of exosomal miRNAs to shuttle through cells in order to transfer genetic material, and thus, play pivotal roles in tumorigenesis and drug resistance [25]. Moreover, an existing study elicited altered tumor growth consequent of intravenously injected exosomal miRNA to the xenograft BC tissues [26]. Our chief findings indicated that exosomal miR-9-5p could confer drug resistance in $\mathrm{BC}$ cells to TAM by regulating ADIPOQ.

The exosomes secreted by the TAM-resistant BC cells (MCF-7/TAM cells) could evidently augment the resistance of MCF-7 cells to TAM, as imitated by repressed cell apoptosis and cell cycle arrest. These findings are broadly aligned with existing evidence eliciting that drugresistant $\mathrm{BC}$ cells could confer the resistance capacity to drug-sensitive cells by secreting exosomes, which partly function by shuttling of specific miRNAs [27]. In consistency with this, Santos et al. demonstrated that exosomesmediated transfer of miRNAs could affect drug resistance in $B C$ cells, thereby surfacing as candidate biomarkers for the investigation of $B C$ progression and therapy [28]. In the current study, our findings revealed that miR-9-5p could repress MCF-7 cell apoptosis and promote the resistance to TAM. The expression of miR- 9 has been implicated with clinicopathological significance in $\mathrm{BC}$ metastasis, whereby its up-regulation can facilitate and hasten the progression of invasive tumors [15]. In addition, an existing study demonstrated an association between miR-9-5p expression in BC and the status of hormone receptors, thus influencing the survival conditions of patients [29]. Besides, an increased expression of miR-9-5p was indicative of a poor prognosis in $B C$ patients with the involvement of oestrogen-regulated pathways [30]. Another study suggested that the miR9-5p expression in the nephrectomy samples could serve as a potential indicator for predicting resistance to firstline therapy in patients with metastatic renal cell carcinoma [31].

Notably, the MCF-7 cells co-cultured with MCF-7/ TAM cell-derived exosomes transfected with miR-9-5p mimic demonstrated radically facilitated cell viability and reduced apoptosis, accompanied by improved resistance to TAM. Cancer cell-derived exosomes containing miRNAs can extensively induce the metastatic potential in recipient cells, during the process of invasion [32]. Therefore, a comprehensive understanding of the role of miRNA in regulation of the tumor microenvironment via exosomes may help develop novel therapeutic agents. For example, exosome-mediated transfer of miR-10b could promote cell invasion in $\mathrm{BC}$ by inhibiting the target genes of HOXD10 and KLF4 [33]. Additionally, an increasing number of studies indicating that exosomal miRNAs may either facilitate or hinder tumor progression by improving drug resistance, and metastatic potential, with regulation of the delivery of tumor-promoting or tumorsuppressive exosomal miRNAs which are regarded as effective treatment strategies $[34,35]$.

Importantly, a combination of bioinformatic analysis and luciferase activity assay verified that ADIPOQ was targeted and negatively regulated by miR-9-5p. ADIPOQ has been proposed to serve as a putative target gene of miR-3634 and was correlated to cell invasion in BC [36]. Supporting findings from an existing study exhibited a correlation between miR-9 expression and the malignant phenotype and chemoresistance of bladder cancer by targeting LASS2 [37]. An overarching finding of this study was observing that exosomal miR-9-5p lowered the ADIPOQ expression to improve the drug resistance in vivo and in vitro. Earlier reports have documented the aggravating role of miR-9 in malignancy. The up-regulation of miR-9 could facilitate metastasis formation in highly malignant cells [38]. MiR-9-5p elicited potential as a catalyst for invasiveness and metastasis by targeting TGFBR2 in non-small cell lung cancer [16]. In the light of existing evidence, our experiments have delineated the 


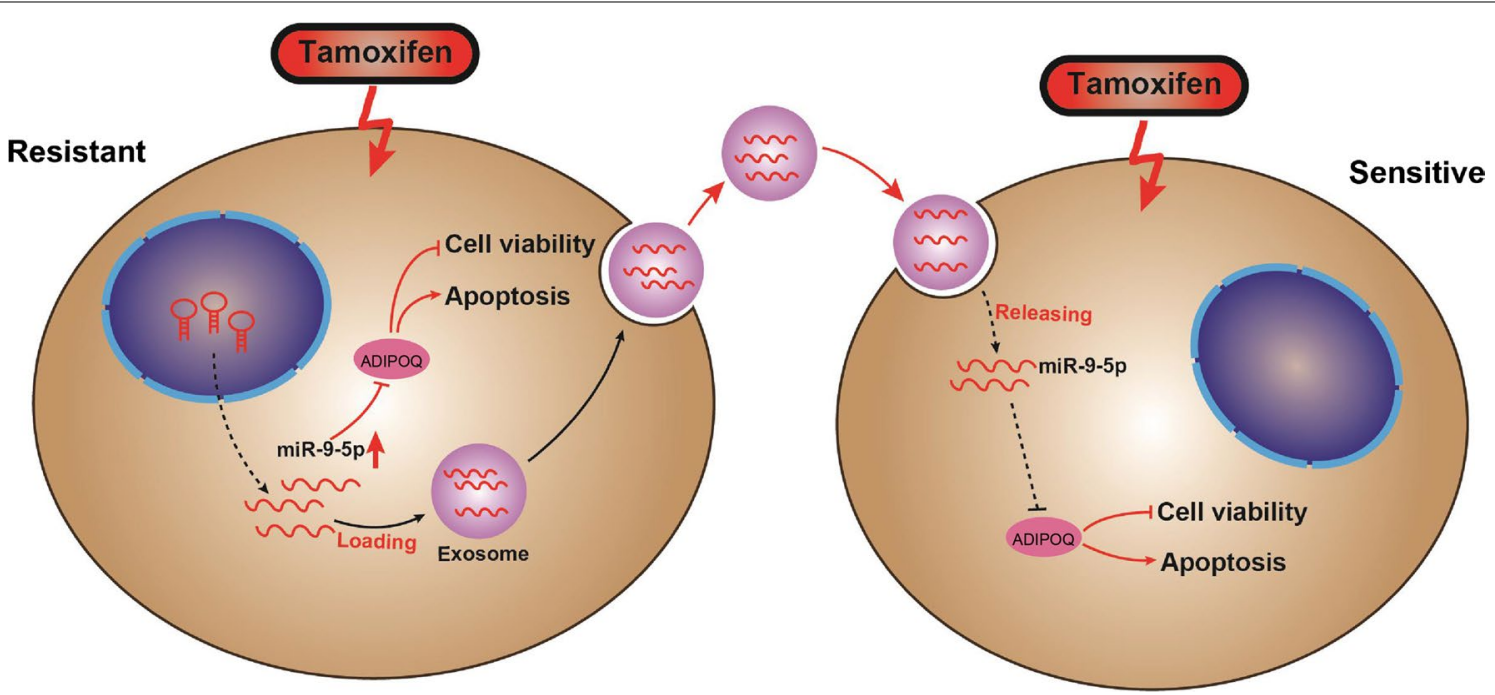

Fig. 9 The schematic representation of the molecular mechanism miR-9-5p in TAM-resistant BC cells. In TAM-resistant BC cells, miR-9-5p promotes TAM resistance by negatively regulating ADIPOQ, whereby it promotes $B C$ cell viability and inhibits apoptosis. In addition, miR-9-5p can be packaged into the exosomes derived from TAM-resistant BC cells, and transferred into the TAM-sensitive BC cells

exosomal miR-9-5p-ADIPOQ interaction as mechanism to alter drug resistance in $\mathrm{BC}$.

Based on the aforementioned evidence, we conclude that exosomal transfer of miR-9-5p facilitated the resistance of $\mathrm{BC}$ cells to TAM by negatively regulating ADIPOQ, and this interaction network could provide an insight on a promising target for the prevention and management of drug resistance in BC (Fig. 9). However, due to the preclinical stage of the current research, further investigations are warranted to elucidate the supporting mechanisms for subsequent clinical translation.

\section{Acknowledgements}

We would like show sincere appreciation to the reviewers for critical comments on this article.

\section{Authors' contributions}

$J \mathrm{~L}, \mathrm{SZ}$ and WT conceived and designed the experiments, participated in its design and coordination, and helped to draft and revise the manuscript. QH, YM and HY collected the samples and clinical data, performed the experiments and the statistical analysis, and drafted the manuscript. JL, SZ and WT collected the samples and clinical data and helped to perform the experiments. All authors participated in the revision of the manuscript. All authors read and approved the final manuscript.

\section{Funding}

This work was supported by "Mechanism of Mir-194-5p targeting Wnt/Bcatenin pathway regulation SATB1 in breast cancer invasion and metastasis" (No.2018GXNSFAA138049) and Mechanism of RSK4-targeted PI3K / AKT Pathway Regulating ACTN4 in Chemotherapy-Resistant Breast Cancer (No. 8186100068).

\section{Availability of data and materials}

The datasets used or analysed during the current study are available from the corresponding author on reasonable request.
Ethics approval and consent to participate

All animal experiments were conducted in compliance with the guidelines of the Guangxi Medical University.

\section{Consent for publication}

Written informed consent for publication was obtained from all participants.

\section{Competing interests}

None.

\section{Author details}

${ }^{1}$ The First Department of Breast Surgery, Guangxi Medical University Cancer Hospital, Nanning 530021, People's Republic of China. ${ }^{2}$ Department of Hepatobiliary Surgery, Guangxi Medical University Cancer Hospital, No.71, Hedi Road, Nanning 530021, Guangxi, People's Republic of China.

Received: 10 August 2020 Accepted: 16 November 2020 Published online: 15 January 2021

\section{References}

1. Thomas ET, Del Mar C, Glasziou P, Wright G, Barratt A, Bell KJL. Prevalence of incidental breast cancer and precursor lesions in autopsy studies: a systematic review and meta-analysis. BMC Cancer. 2017;17(1):808.

2. Phung MT, Tin Tin S, Elwood JM. Prognostic models for breast cancer: a systematic review. BMC Cancer. 2019;19(1):230.

3. Li T, Mello-Thoms C, Brennan PC. Descriptive epidemiology of breast cancer in China: incidence, mortality, survival and prevalence. Breast Cancer Res Treat. 2016;159(3):395-406.

4. Greenlee H, DuPont-Reyes MJ, Balneaves LG, Carlson LE, Cohen MR, Deng G, Johnson JA, Mumber M, Seely D, Zick SM, Boyce LM, Tripathy D. Clinical practice guidelines on the evidence-based use of integrative therapies during and after breast cancer treatment. CA Cancer J Clin. 2017;67(3):194-232.

5. Waks AG, Winer EP. Breast Cancer Treatment. JAMA. 2019:321:288-300.

6. Cykert S. Tamoxifen for breast-cancer prevention. Lancet. 2003;361 (9352):177 (author reply 178).

7. Freedman AN, Graubard BI, Rao SR, McCaskill-Stevens W, Ballard-Barbash R, Gail MH. Estimates of the number of US women who could benefit 
from tamoxifen for breast cancer chemoprevention. J Natl Cancer Inst. 2003;95(7):526-32.

8. Shou J, Massarweh S, Osborne CK, Wakeling AE, Ali S, Weiss H, Schiff R. Mechanisms of tamoxifen resistance: increased estrogen receptor-HER2/ neu cross-talk in ER/HER2-positive breast cancer. J Natl Cancer Inst. 2004;96(12):926-35.

9. Namee NM, O'Driscoll L. Extracellular vesicles and anti-cancer drug resistance. Biochim Biophys Acta Rev Cancer. 2018;1870(2):123-36.

10. Zabeo D, Cvjetkovic A, Lasser C, Schorb M, Lotvall J, Hoog JL. Exosomes purified from a single cell type have diverse morphology. J Extracell Vesicles. 2017;6(1):1329476.

11. Yu DD, Wu Y, Shen HY, Lv MM, Chen WX, Zhang XH, Zhong SL, Tang JH, Zhao JH. Exosomes in development, metastasis and drug resistance of breast cancer. Cancer Sci. 2015;106(8):959-64.

12. Bach DH, Hong JY, Park HJ, Lee SK. The role of exosomes and miRNAs in drug-resistance of cancer cells. Int J Cancer. 2017;141(2):220-30.

13. Kutanzi KR, Yurchenko OV, Beland FA, Checkhun VF, Pogribny IP. MicroRNA-mediated drug resistance in breast cancer. Clin Epigenetics. 2011;2(2):171-85.

14. Luo D, Wilson JM, Harvel N, Liu J, Pei L, Huang S, Hawthorn L, Shi H. A systematic evaluation of miRNA:mRNA interactions involved in the migration and invasion of breast cancer cells. J Transl Med. 2013:11:57.

15. Krell J, Frampton AE, Jacob J, Pellegrino L, Roca-Alonso L, Zeloof D, Alifrangis C, Lewis JS, Jiao LR, Stebbing J, Castellano L. The clinicopathologic role of microRNAs miR-9 and miR-151-5p in breast cancer metastasis. Mol Diagn Ther. 2012;16(3):167-72.

16. Li G, Wu F, Yang H, Deng X, Yuan Y. MiR-9-5p promotes cell growth and metastasis in non-small cell lung cancer through the repression of TGFBR2. Biomed Pharmacother. 2017;96:1170-8.

17. Yang Y, Zhang F, Ding R, Skrip L, Wang Y, Lei H, Hu D. ADIPOQ gene polymorphisms and cancer risk: a meta-analysis. Cytokine. 2013;61(2):565-71.

18. Chung SJ, Nagaraju GP, Nagalingam A, Muniraj N, Kuppusamy P, Walker A, Woo J, Gyorffy B, Gabrielson E, Saxena NK, Sharma D. ADIPOQ/adiponectin induces cytotoxic autophagy in breast cancer cells through STK11/LKB1-mediated activation of the AMPK-ULK1 axis. Autophagy. 2017;13(8):1386-403.

19. Parashar D, Geethadevi A, Aure MR, Mishra J, George J, Chen C, Mishra MK, Tahiri A, Zhao W, Nair B, et al. miRNA551 b-3p Activates an Oncostatin Signaling Module for the Progression of Triple-Negative Breast Cancer. Cell Rep. 2019.29(13):4389-440.

20. Pande M, Bondy ML, Do KA, Sahin AA, Ying J, Mills GB, Thompson PA, Brewster AM. Association between germline single nucleotide polymorphisms in the PI3K-AKT-mTOR pathway, obesity, and breast cancer disease-free survival. Breast Cancer Res Treat. 2014;147(2):381-7.

21. Singh J, Deshpande M, Suhail H, Rattan R, Giri S. Targeted Stage-Specific Inflammatory microRNA Profiling in Urine During Disease Progression in Experimental Autoimmune Encephalomyelitis: markers of Disease Progression and Drug Response. J Neuroimmune Pharmacol. 2016;11(1):84-97.

22. Riancho J, Vazquez-Higuera JL, Pozueta A, Lage C, Kazimierczak M, Bravo M, Calero M, Gonalezalez A, Rodriguez E, Lleo A, et al. MicroRNA Profile in Patients with Alzheimer's Disease: analysis of miR-9-5p and miR-598 in Raw and Exosome Enriched Cerebrospinal Fluid Samples. J Alzheimers Dis. 2017;57(2):483-91.

23. DeSantis C MJ, Bryan L and Jemal A. Breast cancer statistics, 2013. CA Cancer J Clin 2014.64(.
24. Mariotto A, Feuer EJ, Harlan LC, Wun LM, Johnson KA, Abrams J. Trends in use of adjuvant multi-agent chemotherapy and tamoxifen for breast cancer in the United States: 1975-1999. J Natl Cancer Inst. 2002;94(21):1626-34

25. Zhao L, Liu W, Xiao J, Cao B. The role of exosomes and "exosomal shuttle microRNA" in tumorigenesis and drug resistance. Cancer Lett. 2015.356(2 Pt B):339-346.

26. Ohno S, Takanashi M, Sudo K, Ueda S, Ishikawa A, Matsuyama N, Fujita K, Mizutani T, Ohgi T, Ochiya T, et al. Systemically injected exosomes targeted to EGFR deliver antitumor microRNA to breast cancer cells. Mol Ther. 2013;21 (1):185-91.

27. Chen WX, Liu XM, Lv MM, Chen L, Zhao JH, Zhong SL, Ji MH, Hu Q, Luo Z, Wu JZ, et al. Exosomes from drug-resistant breast cancer cells transmit chemoresistance by a horizontal transfer of microRNAs. PLOS ONE. 2014;9(4):e95240

28. Santos JC, Ribeiro ML, Sarian LO, Ortega MM, Derchain SF. Exosomesmediate microRNAs transfer in breast cancer chemoresistance regulation. Am J Cancer Res. 2016;6(10):2129-39.

29. Barbano R PB RM, et al. Abstract 4734: miR-9-5p expression in breast cancer correlates with hormone receptor status and affects patients survival[J]. Cancer Research. 2017.77(.

30. Barbano R, Pasculli B, Rendina M, Fontana A, Fusilli C, Copetti M, Castellana S, Valori VM, Morritti M, Graziano P, et al. Stepwise analysis of MIRS loci identifies miR-9-5p to be involved in Oestrogen regulated pathways in breast cancer patients. Sci Rep. 2017.7(45283.

31. Ralla B, Busch J, Florcken A, Westermann J, Zhao Z, Kilic E, Weickmann S, Jung M, Fendler A, Jung K. miR-9-5p in Nephrectomy Specimens is a Potential Predictor of Primary Resistance to First-Line Treatment with Tyrosine Kinase Inhibitors in Patients with Metastatic Renal Cell Carcinoma. Cancers (Basel). 2018.10(9).

32. Milane L, Singh A, Mattheolabakis G, Suresh M, Amiji MM. Exosome mediated communication within the tumor microenvironment. J Control Release. 2015.219(278-294.

33. Singh R, Pochampally R, Watabe K, Lu Z, Mo YY. Exosome-mediated transfer of miR-10b promotes cell invasion in breast cancer. Mol Cancer. 2014.13(256.

34. Joyce DP, Kerin MJ, Dwyer RM. Exosome-encapsulated microRNAs as circulating biomarkers for breast cancer. Int J Cancer. 2016;139(7):1443-8.

35. Sempere LF, Keto J, Fabbri M. Exosomal MicroRNAs in Breast Cancer towards Diagnostic and Therapeutic Applications. Cancers (Basel). 2017.9(7)

36. Zhang K, Wang YW, Ma R. Bioinformatics analysis of dysregulated microRNAs in the nipple discharge of patients with breast cancer. Oncol Lett. 2017;13(5):3100-8.

37. Wang H, Zhang W, Zuo Y, Ding M, Ke C, Yan R, Zhan H, Liu J, Wang J. miR-9 promotes cell proliferation and inhibits apoptosis by targeting LASS2 in bladder cancer. Tumour Biol. 2015:36(12):9631-40.

38. Ma L, Young J, Prabhala H, Pan E, Mestdagh P, Muth D, Teruya-Feldstein J, Reinhardt F, Onder TT, Valastyan S, et al. miR-9, a MYC/MYCN-activated microRNA, regulates E-cadherin and cancer metastasis. Nat Cell Biol. 2010;12(3):247-56.

\section{Publisher's Note}

Springer Nature remains neutral with regard to jurisdictional claims in published maps and institutional affiliations. 